by Mr. F. A. Kirkpatrick on the literature of travel we meet a number of scientific names in circumstances in which physical and biological science find much of their primary impulse for research. Prof. J. W. Adamson contributes a most valuable chapter on the history of education; and, finally, a chapter on the changes in the language since the time of Shakespeare, by Mr. W. Murison, may be commended to all those who are interested, as all of us ought to be, in the literary exposition of scientific work.

\section{THE RARER ELEMENTS.}

Introduction to the Rarer Elements. By Dr. P. E. Browning. Fourth edition, thoroughly revised. Pp. 250. (New York: J. Wiley and Sons, Inc. ; London : Chapman and Hall, Ltd., I9r7.) Price $7 s$. net.

WE are pleased to find that in spite of the unrest of the present time it has been possible to publish a fourth edition of the above wellknown work. Browning's Introduction to the study of the rarer elements was first published in I 903 as a hand-book for the use of students. The work was successful from the first; a second edition appeared in 1908 , and a third in I9r2. Since then many new facts have been established, and the present issue has been revised and brought up to date, forming a valuable book of reference for practically all that is known about the history, sources, and properties of the rarer elements; numerous reactions are included that will help in the separation and analysis of these little-known bodies.

The general plan of the work is to give particulars of the discovery, occurrence, extraction, and properties of each element, etc., and to conclude with some fractical laboratory work; although the author disclaims any attempt at exhaustive treatment, the student will find much valuable information in its 250 pages. It may be a little startling to the English reader to find in the index to the literature of the subject that, out of twentyfive references quoted, fifteen are American, seven German, two French, and one British! It is only fair, however, to note that most of the American references are from the Smithsonian Collection of Miscellaneous Papers.

All the rarer elements, including the rare earths and the rare gases of the atmosphere, are detailed, and a special chapter is devoted to the radioelements. This latter section, contributed by Prof. B. B. Boltwood, is brief and is confined to the well-established data and reactions of these interesting bodies, and their position in the periodic table. The significance of atomic numbers and the theory of isotopes are also discussed.

In this chapter a good deal of new matter is introduced; among other things it is stated that "the chief source of radium has been the minerals containing a higher proportion of uranium, principally carnotite, and the present supply has been largely obtained from the carnotite ores of south-western Colorado." We rather hesitate to endorse this. Carnotite is a uraniumpotassium-vanadate, and authoritative analyses of picked specimens give about 60 per cent. uranium; but the records of the Bureau of Standards, Washington, show that the commercial ores that are being worked do not contain much more than 2 per cent. uranium. On the other hand, the pitchblende deposits of St. Joachimsthal give 60 per cent. to 80 per cent. $\mathrm{U}_{3} \mathrm{O}_{8}$, and those from Cornwall and other localities are of the same character.

In the section devoted to spectroscopic reactions, a sfectrogram is given of certain gallium and iridium products; this illustration may be of interest from the point of view of pure research, but as a spectrum reproduction it falls very short of what it is possible to do at the present day. The same must be said of the set of six examples of the absorption spectra, of didymium, erbium, etc.; some of these have scales of wave-length that are difficult to read, others are so bad that their value is quite lost, while the erbia series has no scale at all, and in the table of spark spectra of sixteen elements an arbitrary scale is usedthis scale could have been given in Ångström units, which would have added greatly to its value. The list of wave-lengths of the dominant arc and spark lines of the elements is a very good feature and of real value.

A short chapter is devoted to "some technical applications," and many of the more prominent uses to which the rarer elements have been applied are described. This is an exceedingly important section. When we consider that from this group of bodies, many of which but a few years ago were quite unknown and other's simply regarded as chemical and mineral curiosities, have come the incandescent mantle, the metal filament lamp, the pyrophoric alloys, the new steel alloys that are playing such a prominent part in ordnance, naval construction, and engineering, the production of X-rays as in the Coolidge tube, and a host of other minor applications, it must become evident to the most casual observer that the study of these substances gives promise of very substantial reward.

It does not seem too much to suggest that the application of the rarer elements may, in the near future, rival in value the coal-tar and other industries that are at the moment occupying so much attention.

A very interesting diagram is given showing at a glance the chief associates of the rare elements in natural and commercial products, but for some reason that is not clear the radioelements have been left out of this scheme.

We congratulate the author upon the original form of index that has appeared in the last two editions-a device of very great convenience. Against each element is noted the page where the discovery, extraction, compounds, separation, experimental work, spectrum, and technical application are to be found: this enables one to put one's finger in a moment upon any subject needed and is of the greatest convenience.

J. H. Gardiner. NO. 2504, VOL. IOO] 